\title{
The Role of Giving Feedback for Academic Achievement, A Case of Bule Hora University, Ethiopia
}

\author{
Bayisa Bussa Gonfa \\ Department of Natural Resources Management, College of Agriculture Science, Bule Hora University, \\ P.O. Box: 144, Bule Hora, Ethiopia
}

\begin{abstract}
Feedback is an essential component in all learning contexts and without feedback of any kind; we would end up doomed to repeat the same mistakes over and over again. This study was aimed to explore the importance of feedback for academic achievement at Bule Hora University, College of Agricultural Sciences and Natural Resources Management Department. Quantitative and qualitative research design was employed in the study. Qualitative research design was used to explore the perception of respondents toward their educational status and quantitative research design was used to quantify some numerical data that percent and frequency, which was collected in the study college. A total of 47 respondents were used for the study by using the formula recommended by Kather (1985). The study findings indicated that the majority of respondents reflected the importance of feedback 31(65.9\%). According to the finding, requirement of feedback was essential on given assessment types even though vary based on types of assessment. Since feedback is highly correlated with time, instructors are enforced to give feedback on time and students should award more about the values and mechanisms to enforce their instructors. The big problem of feedback was in appropriate follow up time by concerned body in that the department conducts teachers' efficiency at the end of each semester that need to be modified soon.
\end{abstract}

Keywords: Feedback, Perception, Academic, Achievement

DOI: $10.7176 / \mathrm{JEP} / 11-16-01$

Publication date:June 30th 2020

\section{INTRODUCTION}

Feedback is conceptualized as information provided by an agent (e.g., teacher, peer, book, parent, self, experience) regarding aspects of one's performance or understanding (Hyland, 2000; Hattie, 2009). A teacher or parent can provide corrective information, a peer can provide an alternative strategy, a book can provide information to clarify ideas, a parent can provide encouragement, and a learner can look up the answer to evaluate the correctness of a response (Hattie \& Timperley, 2007; Harelli \& Hess, 2008). Feedback thus is a "consequence" of performance. It is one of the most powerful influences on learning and achievement, but this impact can be either positive or negative (ibid).

Winne and Butler (1994) provide that, feedback is an essential part of effective learning. It helps students understand the subject being edited text studied and gives them clear guidance on how to improve their learning. Bellon et al (1991) state 'academic feedback is more strongly and consistently related to achievement than any other teaching behavior...this relationship is consistent regardless of grade, socioeconomic status, race, or school setting. Feedback can improve a student's confidence, self-awareness and enthusiasm for learning (Yorke, 2002). Feedback is an essential component in all learning contexts and serves a variety of purposes including evaluation of students' achievements, development of students' competences, understanding, and elevation of students' motivation and confidence (Hyland, 2000; Shute, 2008). Within teaching and learning activities in a higher education setting, feedback can be perceived as any information communicated to the learner as a result of a learning-oriented action (Race, 2001).

In order to be effective, feedback on formative assessment needs to possess a number of qualities: it needs to be timely, constructive, motivational, personal, manageable and directly related to assessment criteria and learning outcomes (Race, 2001; Juwah et al, 2004; Race, 2006; Irons, 2008). A formative feedback strategy should address as many as possible of these attributes in order to promote learning. The term feedback strategy, however, actually encapsulates two components: the contents of feedback itself and the method(s) used to communicate the feedback to students (Hastie, 2009).

Communication of formative feedback is very important since the method selected may discourage or draw students' attention in the feedback process (Irons, 2008). Formative feedback can be communicated to students in a number of different ways, both traditional and electronic (Race, 2001). Traditional tactics include hand written comments on students' assessed work and print-outs of word-processed feedback forms which are returned back to the students. These traditional ways of communication do not seem to be efficient since they suffer from the problem of not reaching the student (Black, 1998). Electronic feedback methods range from simple techniques such as emailing comments to students to more sophisticated tools that allow tutors to place comments and annotations to electronically submitted work. Electronic feedback methods are increasingly used 
by teachers since they enhance feedback production, delivery and communication (Race, 2001).

Effective and high quality feedback has been identified as an integral part of the learning process (Ramsden, 2003; Black, 1998). Extensive research, not only underpins the importance of feedback in enhancing achievement levels, but also emphasizes the obligation of academic institutions to effectively integrate feedback in the learning experience (Yorke, 2003). Receiving feedback is inherently related to emotion (Higgins, 2000). This is especially true in the case of bad performance where students may feel embarrassment, guilt, anxiety, lack of confidence, confusion, discouragement etc. Therefore, in order to engage students in the feedback process, one must consider students' feelings and tactics for stimulating motivation. Student motivation is a quality that pervades all aspects of learning and, as a result, it is closely associated with the success or failure of any learning system.

Even though different literatures revealed importance of feedback in every level of academic achievement, still date there is a gap and all academicians do not understand about the values of the concept (Chanock, 2000; Winter et al, 2004; Bailey, 2009). Majority of the students at any level of education or training became initiated or enhanced themselves once they know where they are by the activity they performed or they become solution finder for lower performance after feedback. It is true for Ethiopian higher educational institutions/Universities in general and for Bule Hora University in particular that most teachers/Instructors do not perform feedback accordingly by understanding its role in academic achievement for students. Here we aimed to reveal the role of feedback on academic achievement of students in Bule Hora University under college of Agricultural Sciences in Natural Resources Management Department students. Objectives of the study were as follows:

\& To investigate effects of feedback on students' academic performance

* To assess perception of students on academic feedback

$\$$ To draw important information on feedback for academic achievement in general

\section{METHODOLGY}

\subsection{Study area}

Bule Hora University (BHU) is a public higher educational institution established by proclamation no 213/2011 (213/2003 E.C) under Proclamation No. 650/2009. The foundation stone was laid by H.E Dr. Adhanum Haile State Minister, Federal Ministry of Education and H.E Mr. Abadula Gamada President of Oromia regional state on the date of Hidar 8, 2001 E.C. The University is $470 \mathrm{~km}$ to South of Addis Ababa. It is among one of newly established 10 universities and one of the 45 public universities functioning at this time (BHUSL, 2015). Vision of the University is to be one of top five universities at national level and competent in East Africa and beyond by 2030. Its mission is to provide relevant and quality education, to produce competent and ethical graduates, to conduct problem based researches, to give demand driven community services, and also to introduce modern scientific innovation and technology results that contribute to the sustainable development of the country (BHUSL, 2015).

\subsection{Population and Sampling Units}

Population of this research was students of BHU of Agricultural Science College from Natural Resources Management Department. A representative sample was drawn from those students of the study area.

\subsection{Sampling Procedure and sample size}

In this study, Faculty of Agricultural Science was selected purposely due to the researcher was its staff member who initiates him to investigate the issues dealt in this study. Then from the selected faculty's three departments, Department of Natural Resources Management was selected by applying simple random sampling techniques. In order to have a representative sample size for the study, a total list of total Natural Resources Management students were obtained from Registrar Office of BHU. Finally, to conduct the research, a sample size was determined by the formula recommended by Kather (1985). According to the formula used, 47 students were selected from 134 and interviewed in order to infer important conclusions regarding objectives of this research.

\subsection{Methods of Data Collection}

For this study both primary and secondary data were gathered and analyzed. Methods of data collection that used in this study included key informant interviews, focus group discussion and individual student interview. Moreover, secondary data were also collected from official records, research papers, data files from web sites, books, journals.

\subsection{Data Analysis}

In this study both qualitative and quantitative data were collected and analyzed. Descriptive statistics analysis methods such as frequency and percentage were applied to draw some important conclusions. 


\section{RESULTS}

3.1. Perception of respondents on general feedback activity

Table 1: Respondents view about feedback on their academic performance $(n=47)$

\begin{tabular}{lcll}
\hline \hline No & Respondents view & Frequency & Percent $(\%)$ \\
\hline 1 & Positive & 31 & 65.9 \\
2 & Negative & 5 & 10.6 \\
3 & Neutral & 11 & 23.4 \\
\hline \hline
\end{tabular}

Source: Own survey May. 2017

According to (Table 1) explained, respondents were categorized in that 31(65.9\%) were assumed positive values of feedback whereas small number of respondents $5(10.6 \%)$ respond that feedback has negative impact on their academic performance if low mark enrolled. Few respondents 11(23.4\%) responded that they didn't understand either positive or positive values of feedback at all.

\subsection{Respondents view on the need of feedback on different assessment methods}

As respondents' idea, the requirement of feedback on final exam was $43(91.5 \%)$, test $41(87.2 \%)$ and project work also $40(85.1 \%)$. On the other hand, feedback requirement on class work was followed by that on assignment 39(83 \%) and 36(76.6\%) respectively. But number of respondents those said feedback requirement on quiz was majority of the students even though their number was lower than who reflected their idea on the other assessment methods $29(61.7 \%$ ) as explained by table 2 .

Table 2: Respondents view about feedback on different Assessment methods $(\mathrm{n}=47)$

\begin{tabular}{|c|c|c|c|c|c|c|}
\hline \multirow[b]{2}{*}{ Assessment methods } & \multicolumn{6}{|c|}{ "Respondents View on Feedback Requirement } \\
\hline & Need & Frequency & $(\%)$ & Not need & Frequency & $(\%)$ \\
\hline Quiz & Yes & 29 & 61.7 & No & 18 & 38.3 \\
\hline Test & Yes & 41 & 87.2 & No & 6 & 12.8 \\
\hline Assignment & Yes & 36 & 76.6 & No & 11 & 23.4 \\
\hline Project work & Yes & 40 & 85.1 & No & 7 & 14.9 \\
\hline Class work & Yes & 39 & 83 & No & 9 & 17 \\
\hline Final exam & Yes & 43 & 91.5 & No & 4 & 8.5 \\
\hline
\end{tabular}

Source: Own survey May. 2017

\subsection{Relationships between feedback and time for academic achievement}

Table 3: Relationships between feedback and time according to sampled respondents $(n=47)$

\begin{tabular}{lcccccc}
\hline \multirow{2}{*}{ Time of feedback } & \multicolumn{2}{c}{ Positive Effects } & \multicolumn{2}{c}{ Negative } & Effects & \multicolumn{2}{c}{ No effects } \\
\cline { 2 - 7 } & Frequency & $\mathbf{( \% )}$ & Frequency & $\mathbf{( \% )}$ & Frequency & $\mathbf{( \% )}$ \\
\hline At a time & 33 & 70.2 & 3 & 6.4 & 11 & 23.4 \\
<1 week & 17 & 36.2 & 13 & 27.7 & 17 & 36.2 \\
1 week & 5 & 10.6 & 31 & 65.9 & 11 & 23.4 \\
> week & 9 & 19.1 & 32 & 68.1 & 6 & 12.8 \\
If not at all & 3 & 6.4 & 36 & 76.6 & 8 & 17 \\
\hline \hline
\end{tabular}

Source: Own survey May. 2017

According to respondents perception (Table 3) if feedback given immediately, it has high positive values $33(70.2 \%)$ and if delayed more than a week it has high negative value $32(68.1 \%)$. If the delay of feedback is not more than a week, there may lower negative effects on students' academic achievement 13(27.7\%).

Table 4: Reason behind to delay/avoid giving feedback for students $(n=47)$

\begin{tabular}{clcc}
\hline \hline No. & \multicolumn{1}{c}{ Reason to delay/avoidance of feedback } & Frequency & Percent \\
\hline 1 & Shortage of time for teachers & 3 & 6.4 \\
2 & Low concern by teachers & 9 & 19.1 \\
3 & Low concern by students & 5 & 10.6 \\
4 & There is no legislation enforcing teachers & - & - \\
5 & Low follow up from concerned body & 11 & 23.4 \\
6 & In appropriate follow up time by concerned body & 15 & 31.9 \\
7 & Fear of the consequences for next assessment & 4 & 8.5 \\
\hline \hline
\end{tabular}

According to result in table 4, majority of the respondents agree that there was in appropriate time to follow up the process of giving feedback $15(31.9 \%)$ followed by low follow up by concerned body $11(23.4 \%)$. Low concern by some teachers $9(19.1 \%)$, Low concern by some students $5(10.6 \%)$ and fear of consequences for the next assessment were respondents reflection during interviewing. 


\section{DISCUSSION}

In this study a total of 47 sample sizes were taken. Of these, $65.9 \%(\mathrm{n}=31)$ were perceived that taking feedback has positive effects on their academic achievement whereas $23.4 \%(\mathrm{n}=11)$ perceived neither positive nor negative effects of the action. On the other hand, only $10.6 \%(\mathrm{n}=5)$ considered the negative effects of feedback action on academic achievement. Based on the result, researcher revealed that giving feedback plays a major role in enhancing students' performance on their academic issue. This result concurs with previous researches (Bellon et al., 1991) which state 'academic feedback is more strongly and consistently related to achievement than any other teaching behavior. Similarly, Hyland (2000) reported feedback is an essential component in all learning contexts and serves a variety of purposes including evaluation of students' achievements, development of students' competences, understanding, and elevation of students' motivation and confidence. There was some exceptional finding that some respondents perceived the negative effects of feedback on their overall performance. This may linked with emotional reflection on some individuals if they recorded lower mark. This finding was in lined with other researcher that, receiving feedback is inherently related to emotion (Higgins, 2000). This is especially true in the case of bad performance where students may feel embarrassment, guilt, anxiety, lack of confidence, confusion, discouragement etc. as this above author.

According to result gained, giving feedback for academicians was very important in all assessment types (Quiz, test, project work, assignment, class work, final exam) even though the level of requirement was differ. Similar study revealed that assessment needs not only provide feedback to students about their learning, but could and should also provide feedback to teachers about their methods (Hattie, 2009). Other supportive conclusion also drawn by Winne and Butler (1994) provide that, feedback is an essential part of effective learning. It helps students understand the subject being edited text studied and gives them clear guidance on how to improve their learning. Bellon et al (1991) state 'academic feedback is more strongly and consistently related to achievement than any other teaching behavior...this relationship is consistent regardless of grade, socioeconomic status, race, or school setting. Feedback can improve a student's confidence, self-awareness and enthusiasm for learning (Yorke, 2002).

According to respondents perception, if feedback given immediately, it has high positive values and if delayed more than a week it has high negative effects. But if the delay of feedback not more than a week it may lower negative effects on students' academic achievement. The other study revealed that in order to be effective, feedback on formative assessment needs to possess a number of qualities: it needs to be timely, constructive, motivational, personal, manageable and directly related to assessment criteria and learning outcomes (Race, 2001; Juwah et al, 2004; Race, 2006; Irons, 2008).

In some cases, respondents outlined that giving feedback is more important for clever students than lower grade enroller due to fear and tension for next exam. As other researcher confirmed, receiving feedback is inherently related to emotion (Higgins, 2000). This is especially true in the case of bad performance where students may feel embarrassment, guilt, anxiety, lack of confidence, confusion, discouragement etc. This was not the case for highly confident students as they prepare themselves further for the next assessment if feedback given on time as respondents reflected. This conclusion was also supported by Hyland (2000) and Shute (2008) as feedback is an essential component in all learning contexts and serves a variety of purposes including evaluation of students' achievements, development of students' competences, understanding, and elevation of students' motivation and confidence.

The big problem of feedback was in appropriate follow up time by concerned body in that the department conducts teachers' efficiency at the end of each semester. This allowed some teachers pass giving of feedback on time or avoid completely. Supportive ideas by different authors conducted as follow: In order to be effective, feedback needs to possess a number of qualities: it needs to be timely, constructive, motivational, personal, manageable and directly related to assessment criteria and learning outcomes (Race, 2001; Juwah et al, 2004; Race, 2006; Irons, 2008). There was also low follow up and low concern by some teachers according to the respondents' justification. The other finding ensures that, effective and high quality feedback has been identified as an integral part of the learning process (Ramsden, 2003; Black, 1998). Extensive research, not only underpins the importance of feedback in enhancing achievement levels, but also emphasizes the obligation of academic institutions to effectively integrate feedback in the learning experience (Yorke, 2003).

\section{CONCLUSION}

There is a lot known about feedback, but there is much more to know about how to optimize its powers in the classroom. Given the high levels of variability in the effectiveness of feedback, more research including the current study is needed on how to ensure feedback in classrooms. It is best if the criteria of success are transparent and understood, and that the student has commitment and skills in investing and implementing strategies as well as understandings relative to these goals and success criteria. Indeed, there is an exciting future for research on feedback. It is becoming well understood that feedback is critical to raising academic achievement of students. In this light, the paucity of feedback in the classroom, at least in the sense of feedback 
that is received and understood by students, is an important conundrum. It probably requires better understanding of classroom dynamics, and providing other ways for teachers to see learning than merely through the eyes and reflection.

\section{ACKNOWLEDGEMENTS}

I would like to duly acknowledge the staffs of Bule Hora University for their cooperation and assistance during data collection. Finally, I would like to express my heartedly thanks to respondents for this research.

Competing Interests: The author declare that no competing interest exist.

\section{REFERENCES}

Bailey, R. 2009. "Undergraduate Students' Perceptions of the Role and Utility of Written Assessment Feedback".Journal of Learning Development in Higher Education, no. 1, pp. 1-14, [Online], http://www.aldinhe.ac.uk/ojs/index.php?journal=jldhe\&page=index

Bellon, J.J., Bellon, E.C. \& Blank, M.A. 1991. Teaching from a Research Knowledge Base: a Development and Renewal Process. Facsimile edition. Prentice Hall, New Jersey, USA.

Bule Hora University Senate Legislation. 2015. (Unpublished material)

Black, P. and William, D. 1998. "Assessment and Classroom Learning”, Assessment in Education: Principles, Policy \& Practice, 5(1), 7-74.

Bradbury, T.N., \& Fincham, F.D. 1990. Attributions in marriage: Review and critique. Psychological Bulletin, $107,3-23$.

Brutus, S., \& Greguras, G.J. 2008. Self-construals, motivation, and feedback-seeking behaviors. International Journal of Selection and Assessment, 16(3), 282-291.

Camus, A. \& O’Brien, J., 1975. The myth of Sisyphus, published by Penguin books.

Carless, D. 2006. Differing perceptions in the feedback process. Studies in Higher Education, 31(2), 219-233.

Carroll, A., Houghton, S., Durkin, K., \& Hattie, J.A.C. 2009. Adolescent Reputations and Risk: Developmental trajectories to delinquency. NY: Springer.

Chan, C.Y.J. 2006. The effects of different evaluative feedback on student's self-efficacy in learning. Unpublished PhD, University of Hong Kong.

Chanock, K. 2000.“Comments on Essays: Do Students Understand What Tutors Write?”, Teaching in Higher Education, 5(1), 95-105.

Harelli, S., \& Hess, U. 2008. When does feedback about success at school hurt? The role of causal attributions. Social Psychology in Education, 11, 259-272.

Hattie, J.A.C., \& Timperley, H. 2007. The power of feedback. Review of Educational Research, 77(1), 81-112.

Hattie, J. A.C. 2009. Visible learning: A synthesis of 800+ meta-analyses on achievement. Routledge, Oxford, UK.

Heimbeck, D., Frese, M., Sonnentag, S., \& Keith, N. 2003. Integrating errors into the training process: The function of error management instructions and the role of goal orientation. Personnel Psychology, 56, 333362.

Higgins, R., Hartley, P., \& Skelton, A. 2001. Getting the message across: The problem of communicating assessment feedback, Teaching in Higher Education, 6(2), 269-274.

Higgins, R. 2000. "Be more critical!" Rethinking assessment feedback. Paper presented at the British Educational Research Association Conference Cardiff University, September 7-10 2000, [Online] http://www.leeds.ac.uk/educol/documents/00001548.htm.

Hyland, F., \& Hyland, K. 2000. Sugaring the pill: Praise and criticism in written feedback. Journal of Second Language Writing, 10(3), 185-212.

Irons, A. 2008. Enhancing learning through formative assessment, Routledge, London.

Juwah, C., Macfarlane-Dick, D., Matthew, B., Nicol, D., and Smith, B. 2004. Enhancing Student Learning though Effective Formative Feedback, The Higher Education Academy, [Online],

Kang, S., McDermott, K. B., \& Roediger, H. L. 2007. Test format and corrective feedback modulate the effect of testing on memory retention. The European Journal of Cognitive Psychology, 19, 528-558

Kung, M.C. 2008. Why and how do people seek success and failure feedback? A closer look at motives, methods and cultural differences. Unpublished doctoral dissertation, Florida Institute of Technology

Kulhavy, R. W. 1977. Feedback in written instruction. Review of Educational Research, 47(1), 211-232.

Luque, M.F., \& Sommer, S.M. 2000. The impact of culture on feedback-seeking behavior: An integrated model and propositions. The Academy of Management Review, 25(4), 829-849.

Nickerson, R.S. 1998. Confirmation bias; A ubiquitous phenomenon in many guises. Review of General Psychology, 2 (2), 175-220.

Nuthall, G. 2007. The Hidden Lives of Learners. Wellington, New Zealand: New Zealand Council for Educational Research. 
Race, P. 2001. Using Feedback to Help Students Learn, The Higher Education Academy, [Online], http://www.heacademy.ac.uk/resources/detail/id432 using feedback

Race, P. 2006. The Lecturer's Toolkit - A Practical Guide to Assessment, Learning and Teaching, 3rd Edition, Routledge, London.

Ramsden, P. 2003. Learning to Teach in Higher Education, 2nd Edition, Routledge, London.

Smith S. L. 2009. Academic target setting: Formative use of achievement data. Unpublished Doctoral Thesis, University of Auckland.

Shute, V.J. 2008. Focus on formative feedback, Review of Educational Research, 78(1), p153-189.

Winne, P. H., \& Butler, D. L. 1994. Student cognition in learning from teaching. In T. Husen \& T. Postlewaite (Eds.), International encyclopaedia of education (2nd ed., pp. 5738-5745). Oxford, UK: Pergamon.

Winter, C. and Dye, V.L. 2004. "An Investigation into the Reasons Why Students Do Not Collect Marked Assignments and the Accompanying Feedback", CELT Learning and Teaching Projects 2003/04.

Yorke, M. 2002. "Formative Assessment in Higher Education: Moves towards Theory and the Enhancement of Pedagogic Practice", Journal of Higher Education, 45(4):471-501. 